\title{
PRELIMINARY TESTS OF VIBRATION RESISTANCE OF HYDRAULIC MICROVALVES
}

\author{
M. Stosiak ${ }^{*}$ K. Towarnicki** ${ }^{* *}$ M. Lubecki***
}

\begin{abstract}
This paper presents the requirements which microhydraulic systems are expected to meet. Disturbances to the operation of the systems are indicated. A preliminary test stand for identifying the effect of external mechanical vibrations on microhydraulic components is described. The relief microvalve as a representative microhydraulic component was subjected to mechanical vibrations.
\end{abstract}

Key words: microhydraulics, pressure relief valve, vibration, pressure fluctuation

\section{Introduction}

Operating machines and equipment incorporating microhydraulic systems generate (free, forced, selfexcited, etc.) mechanical vibrations within a wide frequency spectrum (Stosiak, 2015). Vibrations coming from the outside are transmitted via the foundation and their sources can be: street traffic (Engel and Zawieska, 2010), railway traffic (Grajnert, 1997), machines working close to buildings and manufacturing sheds, and explosions. Fluid pressure fluctuations in a microhydraulic system can be caused by fluctuations in the rate of working fluid delivery (Kollek, 2011), due to the operational kinematics of the micropump's displacement elements. Micropump delivery fluctuations in a microhydraulic system generate periodically variable pressures the graph of which has the shape of a harmonic function. The frequency of the pressure fluctuations corresponds to the frequency of the delivery rate fluctuations (Kudźma, Kułakowski and Stosiak, 2014). Micropump delivery fluctuations also induce mechanical vibrations of, e.g., microhydraulic conduits by Stosiak (2015), as illustrated in Fig. 1. In the spectrum shown in Fig. 1 one can observe harmonic mechanical vibration components corresponding to pressure fluctuations (flowing fluid pressure fluctuations induced by the mechanical vibrations of the hydraulic conduit). The main requirements which microhydraulic components and systems are expected to meet are: operational reliability, a low noise level (not exceeding the allowable (ever lower) values) (Byung-Phil, et al., 2003), small dimensions at unreduced transferred power, and drive cleanness (no leakages) in some special applications.

Prof. Michał Stosiak, Wrocław University of Science and Technology, Faculty of Mechanical Engineering, Department of the Operation of Logistic Systems, Transport Systems and Hydraulic Systems, Łukasiewicza 7/9, 50-371 Wrocław, michal.stosiak@pwr.edu.pl

** Krzysztof Towarnicki, MSc., Wrocław University of Science and Technology, Faculty of Mechanical Engineering, Department of the Operation of Logistic Systems, Transport Systems and Hydraulic Systems, Łukasiewicza 7/9, 50-371 Wrocław, krzysztof.towarnicki@pwr.edu.pl

**** Marek Lubecki, MSc., Wrocław University of Science and Technology, Faculty of Mechanical Engineering, Department of the Operation of Logistic Systems, Transport Systems and Hydraulic Systems, Lukasiewicza 7/9, 50-371 Wrocław, marek.lubecki@pwr.edu.pl 


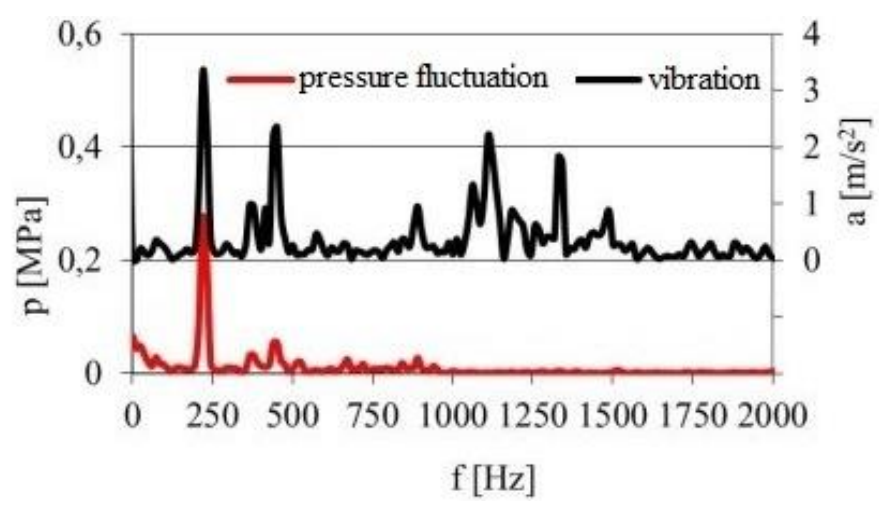

Fig. 1: Amplitude-frequency spectrum of microhydraulic conduit pressure fluctuation and mechanical vibration, $p=5 \mathrm{MPa}, Q=1.83 \times 10^{-5} \mathrm{~m}^{3} / \mathrm{s}\left(1.1 \mathrm{dm}^{3} / \mathrm{min}\right)$.

\section{Test stand}

The test stand shown in Fig. 2 was built to examine the effect of external mechanical vibrations on hydraulic microvalves and their control components.

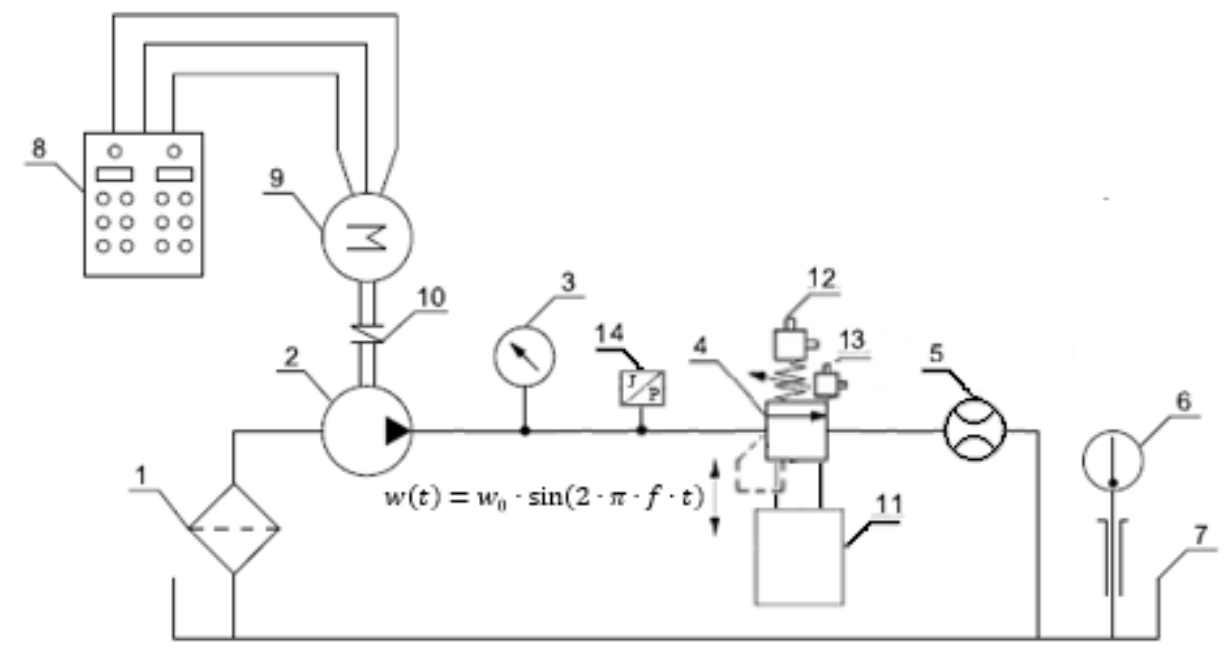

Fig. 2: Diagram of hydraulic system for examining effect of external mechanical vibrations on hydraulic microvalves: 1 -oil filter, 2 - gear pump WPH PZ3A1G, 3 - pressure gauge Parker ServiceJunior SCJN-400-01, 4-tested microvalve, 5-flowmeter Parker KSCVF-002-10-07X, 6-thermometer Elmetron PT-217, 7 - oil tank, 8-control gear cabinet, 9 - three-phase electric motor, 10 - torque indicator, 11 - vibration exciter Tira Vibration Test Systems TV 51144,

12, 13 - acceleration PCB sensors Piezotronics 340A16 and 356B21, 14- pressure PCB sensor Piezotronics 105C23.

Preliminary tests on the stand for testing the vibration resistance of hydraulic microvalves began with the calibration of the system components to ensure correct measurements. For this purpose the uniaxial accelerometer to be used for testing was mechanically attached to a calibrator whose vibration frequency and amplitude were known. When the values measured by the accelerometer and recorded by a data acquisition board were confirmed by the values generated by the calibrator, the next test step began. The uniaxial accelerometer was installed in the line of vibrations generated by the vibration exciter. Series of measurements were performed under a constant vibration acceleration of $10 \mathrm{~g}$ for the excitation frequency of $200-1100 \mathrm{~Hz}$ at a step of $20 \mathrm{~Hz}$. Fluid used in the system was Azolla 22AF hydraulic oil, with properties:

- $\varrho=865 \mathrm{~kg} / \mathrm{m}^{3}$,

- $v\left(40{ }^{\circ} \mathrm{C}\right)=22.5 \mathrm{~mm}^{2} / \mathrm{s}$,

Reynolds number of the flow, calculated as: $\mathrm{Re}=2 \mathrm{Q}_{\mathrm{z}} /(\pi \mathrm{d} v)$ (Figiel, Kudźma, Stosiak, 2016), was equal to 57.5 . 


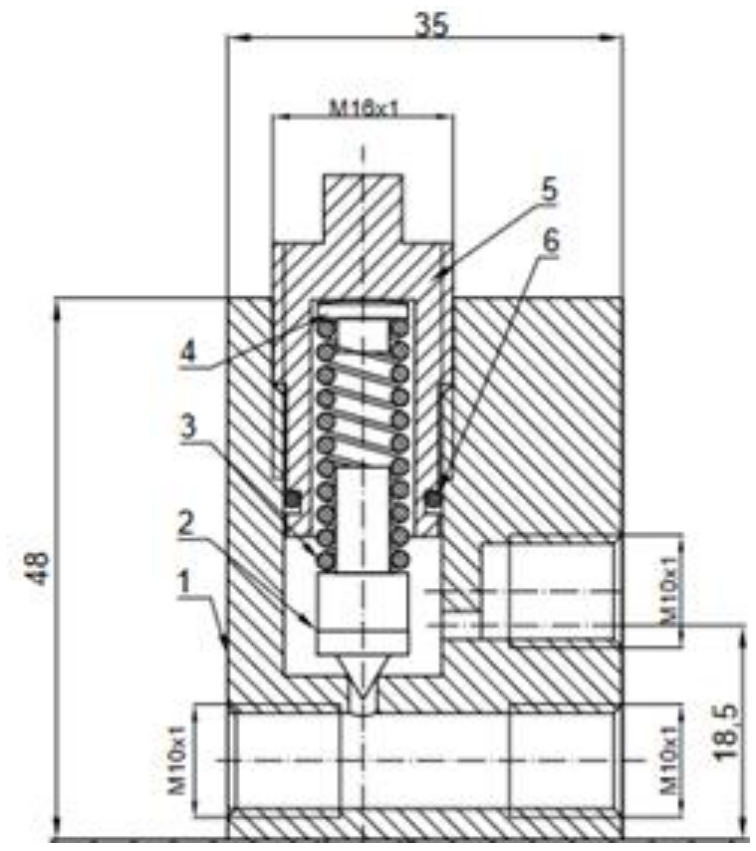

Fig. 3: Axial micro section of the relief valve: 1 -body, 2 - poppet, 3-spring, 4 -spacer, 5 -screw, $6-$ seal.

Dedicated software PUMA, enabling the remotely controlled starting, ending and recording of measurements, was used for communicating with the data board. The data were further processed in Origin Pro 9.

\section{Test results}

For the main tests the hydraulic system was started. Pressure fluctuation measurements were performed without applying external mechanical vibrations to the valve housing (Fig. 4).

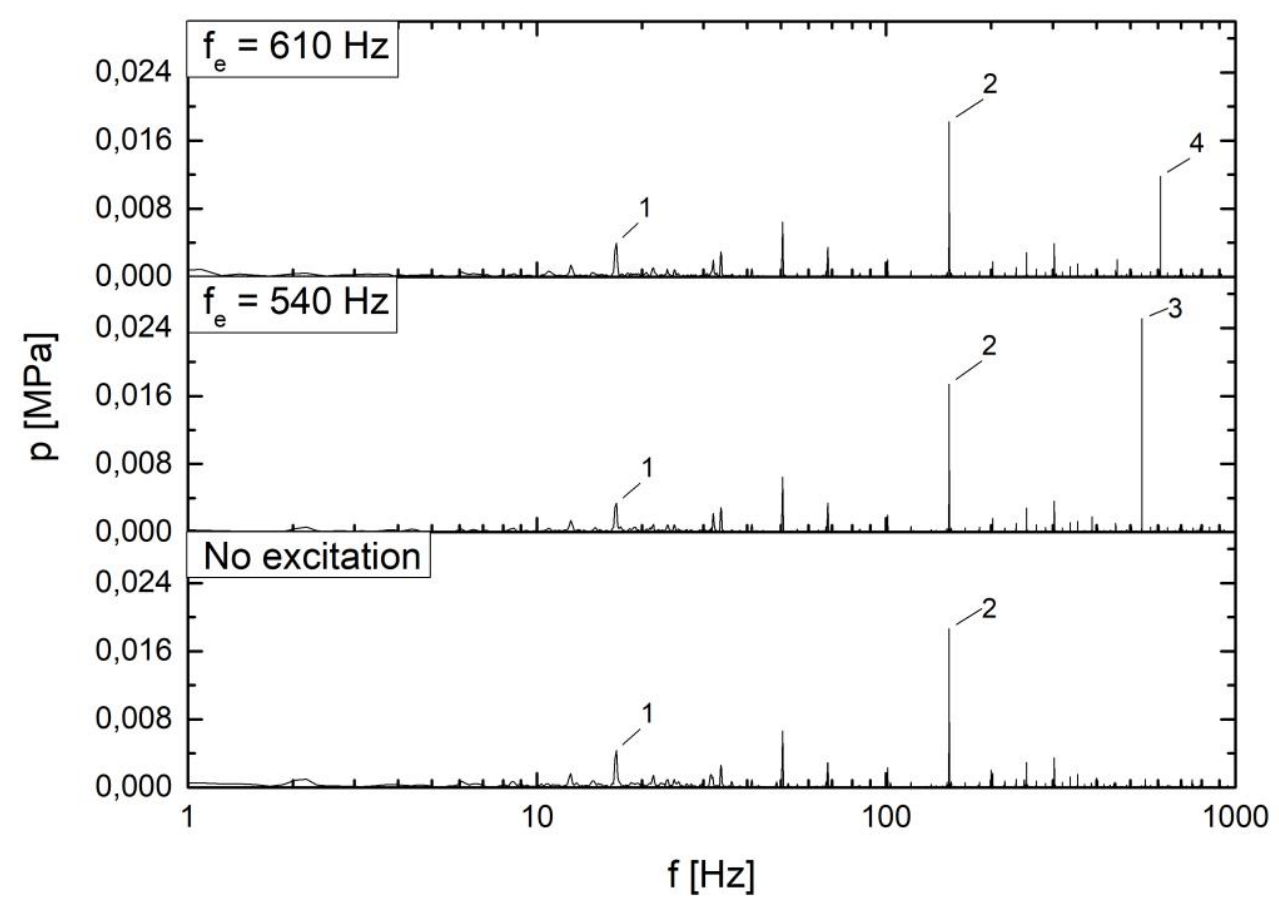

Fig. 4: Pressure fluctuation amplitude for different excitation frequencies $\left(f_{e}\right)$ versus frequency at $n=1000 \mathrm{rpm}, p_{a v}=5 \mathrm{MPa}, Q=1 \times 10^{-5} \mathrm{~m}^{3} / \mathrm{s}\left(0.6 \mathrm{dm}^{3} / \mathrm{min}\right)$. 
Then measurements were carried out with external mechanical vibrations applied to the relief microvalve housing. The specifications of the vibrations were the same as during the testing of the vibration generation circuit. The measurement results are presented in Fig. 4. An external gear pump with nine teeth was used in the measurements. In the pressure fluctuation amplitude-frequency spectrum one can identify an additional component (3) stemming from the action of the external mechanical vibrations. Its value is relatively high due to the excitation of microvalve head vibrations, causing additional pressure fluctuations. Also one can distinguish an additional component (3) stemming from the external vibrations, but its value is considerably lower since the vibration frequency significantly differs from the resonance frequency of the microvalve. The next lower components in the pressure fluctuation spectrum correspond to: (2) displacement pump delivery fluctuation and (1) drive shaft imbalance.

\section{Conclusion}

Microhydraulics is one of the most intensively developing areas of hydraulics. It finds ever new applications. The experimental results indicate that the tested lift valve subjected to external mechanical vibrations is a source of additional components in the spectrum of the pressure fluctuation in the microhydraulic system. The amplitudes of the additional pressure fluctuation spectrum components increase close to the resonance of the head of the tested microvalve (Figiel, Kudźma and Stosiak, 2016). This can result in additional mechanical vibrations of the hydraulic conduits, the unsteady work of the microhydraulic receivers and increased noisiness of the operation of the systems. It should be noted that because of the through-port diameters microhydraulic components and systems are highly sensitive to obliteration. Moreover, the relevant EU directives (2000/14/EC of 8 May 2000) relate the allowable level of noise emitted by mechanical equipment to the transmitted power. The allowable level of noise in microhydraulic systems is relatively low and despite the advantages of this type of drive, the latter cannot always be used due to the exceedance of the recommended standard indicators (Kollek, 2011). Therefore, both theoretical and experimental research is conducted to develop passive methods of reducing pressure fluctuations and mechanical vibrations and implement them in microhydraulic systems.

\section{References}

Byung-Phil M., Mi-Young S., Ho-Seung J. and Chul-Ju K. (2003) Fabrication of a No-Leakage Micro-Valve with a Free-Floating Structure for a Drug-Delivery System. Journal of the Korean Physical Society, Vol. 43, No. 5, pp. 930-934.

Engel Z. and Zawieska M. (2010) Noise and vibrations in work processes: sources, assessment, hazards, CIOP-PIB, Warsaw (in Polish).

European Parliament and Council Directive 2000/14/EC of 8 May 2000 on the approximation of the laws of the Member States relating to the noise emission in the environment by equipment for use outdoors.

Figiel A., Kudźma Z. and Stosiak M. (2016) Evaluation of dynamic properties of relief microvalve Problems relating to development of construction machinery: 29th Scientific Conference: papers, Zakopane (in Polish)., 25-27 January 2016: Institute of Mechanised Construction and Rock Mining, pp. 1-12.

Grajnert J. (1997) Isolation of vibrations in machines and vehicles, Wrocław University of Science and Technology Publishing House, Wrocław (in Polish).

Kollek W. ed. (2011) Fundamentals of design, modelling and operation of microhydraulic components and systems, WUST Publishing House, Wrocław (in Polish).

Kudźma Z., Kułakowski K. and Stosiak M. (2014) Selected problems in operation of microhydraulic systems. Napędy i sterowanie, 2014, Vol. 16, No. 4, 78-83.

Stosiak M. (2015) Identification of impact of vibrations and methods of reducing them in selected hydraulic valves, Wrocław (in Polish). 